\title{
Research on Measures for Protecting Consumers' Personal Information Security in Express Industry
}

\author{
Jing Cui \\ Baicheng Normal University \\ Baicheng, China
}

\begin{abstract}
With the coming of the era of big data, the leakage of such consumers' personal information as receiving express services becomes more and more serious, and the number of civil and criminal cases caused for such reason is increasingly increased. This paper analyzes the reasons for leakage of large amount of consumers' information in express industry from four aspects, and puts forward measures for protecting consumers' personal information in express industry.
\end{abstract}

Keywords-express industry; consumer; personal information; protection; prevention measures

\section{INTRODUCTION}

In recent 20 years, with the rapid development of online shopping platform in China, online shopping has become one of the most popular shopping methods. The rapid development of online shopping requires express industry to provide strong support in distribution of commodities. Therefore, express companies emerge at the right moment. However in the context of the rapid development of express companies, it may also be found that the leakage of consumers' personal information on express waybill has caused many civil and criminal cases, and become one of the most worrying and most concerned issues for the majority of online consumers. Express information security issues are receiving more and more attentions.

\section{THE CONCEPT OF CONSUMERS' PERSONAL INFORMATION IN EXPRESS SERVICES}

The term "personal information" gradually entered people's vision along with the development of e-commerce. But what on earth is the concept of personal information? What are the factors that this concept contains? No matter in the current Criminal Law, the General Provisions of Civil Law, the Tort Liability Law, or the Consumer Protection Law, it just uses the word "personal information" simply, without any specific provisions for the concept of personal information. As a result, this may lead to a lack of uniform standards for the identification of personal information. In express industry, consumers' personal information should refer to such user's name, address, mobile phone number and other information on the express waybill as is personally symbolic and can further identify the personal characteristics.

\section{The Status QUO OF CONSUMERS' PERSONAL INFORMATION PROTECTION IN EXPRESS INDUSTRY}

\section{A. The Status Quo of Express Company's Protection on Consumers' Personal Information}

Since the express company is responsible for distributing commodities from one party to the other party of a sales contract, it is necessary to collect the personal information of both parties of the contract in the service providing process and it is also in compliance with the law. But after the collection, express waybills filled with consumers' personal information are arbitrarily thrown away for reason that the business operator has not that strong sense of responsibility or wants to save cost or are not timely destroyed as per relevant provisions of the enterprise. This provides a chance for those aiming to steal consumers' information on the waybill. What's more, some express companies' workers directly sell the express waybills in specific price and made huge profits from it, forming a "gray" industrial chain to buy and sell consumers' personal information.

\section{B. The Status Quo of Current Legislation on Protection of Consumers' Personal Information in Express Industry}

In China, in the article 28 of the Measures for Management of Express Market and the Provisions for Management of User's Personal Information Security under Express Service and the Measures for Management of Express Market, it is specified that express practitioners are prohibited to illegally provide user's information and otherwise will be punished accordingly. However, these three regulations are formulated and issued by the Ministry of Transport and the State Post Bureau, belong to departmental regulations and have a lower level of effectiveness in law. They cannot effectively protect the personal information of consumers in express industry. Although the "Postal Law" and "Consumer Protection Law" in legal level also have provisions for consumers' personal information protection, the provisions are more in principle and are difficult to be implemented effectively. The Criminal Law is the last barrier for protecting consumers' personal information in express industry. But, it only specifies that only those disclose information seriously can be punished according to the criminal law. However in real life, many express workers' extents of leaking consumers' personal information are not serious. After analyzing the current situation of consumer's personal information protection in 
current legislation of China, it is known that although there are many relevant regulations, there is not a complete and systematic legal system. It is difficult to form a direct, effective and comprehensive protection mechanism for consumers' personal information in express industry.

\section{REASONS FOR THE LEAKAGE OF CONSUMERS PERSONAL INFORMATION IN EXPRESS INDUSTRY}

\section{A. The Market Has High Demands for Consumers Personal Information}

In recent years, the development of network technology and information technology and the tendency of economic globalization changed the traditional marketing and consumption methods to some extent. In the era of underdeveloped science and technology, operators have no way to efficiently obtain information having personality characteristics such as consumers' personal information, consumption demand and consumption propensity due to the backward information collection methods so that operators provide consumers with commodities or services to a large spontaneous and blind extent. While under the premise of the developed science and technology today, operators can use various information collection methods to collect such information at a low cost and high efficiency and make a scientific analysis on the collected information, getting consumers' consumption habits and consumption trends, so as to effectively provide personalized services for specific consumers, and further gain competitive advantage in the market. It is right because of the market operators' such high demand for personal information of consumers that express companies and practitioners may take the change to leak personal information of the consumers in order to gain private interest.

\section{B. Internal Supervision of Express Company Is Ineffective and the Quality of Express Practitioner Is Not High}

The large amount leakage of consumers' personal information is not that closely related to the internal supervision of express companies. Express companies have insufficient management on the protection of consumers' personal information. Especially, there is obvious bug in daily management of express waybills. In addition, the management on use, recycling, preservation and destruction of express waybills is at will over much and they bear no responsibility for protection of consumers' personal information. At the same time, with the rapid development of express industry, the demand for express practitioners is increased dramatically. It is for such reason that, in recruiting employees, express companies usually may not pay attention to the quality, educational background and qualification of the applicants and even directly omit the induction training in order to let the selected personnel work as soon as possible. Consequently, the practitioners' professional quality and service quality are relatively poor. Moreover, express companies' assessment mechanisms for professional ethics and quality of its employees are not perfect, which ultimately leads to the illegal behavior of employees who violate the lawful rights and interests of consumers, such as self-stealing and selling consumers' personal information.

\section{Express Industry Has Incomplete Legislation for Protection of Consumers' Personal Information}

As aforementioned, there is no specific personal information protection law in China.

Although in the Measures for Management of Express Market, the Provisions for Management of User's Personal Information Security under Express Service, Postal Law, Criminal Law and Consumer Protection Law, it is specified that express practitioners are prohibited to illegally provide user's information and otherwise will be punished accordingly, the provisions are not complete and systematic and are hard to provide direct, effective and comprehensive protection for consumers' personal information in express industry. Therefore in current stage, it is urgently needed to establish a special legislation for protection of personal information in order to protect the security of consumers' personal information.

\section{Consumers Have Weak Awareness of Self-protection}

As for leakage of consumers' personal information in express industry, one of the important reasons is that consumers also have weak awareness of self-protection, in addition to venality behaviors of express companies and practitioners.

1) Consumers may randomly throw away express waybills: Many online shopping consumers pay not enough attention to the protection of their personal information. What they commonly do after sign in the express waybill and take out the purchased commodity is to randomly throw away the packaging box pasted with the express waybill. But they ignore that the waybill contains personal information very important to them. As a result, they may get stuck in unbearable event if such important personal information is used by sinister lawbreakers in the society to fraud, blackmail and rob them.

2) Consumers may randomly download software with hidden risk: For ordinary consumers, they are only very familiar with the shopping operational process but lack of deep understanding of the risk existing in online shopping. For example, consumers may get their real and detailed residential address set up as the default receiver address for online shopping, without even notice the existence of risk. Additionally, consumers may not regularly kill virus and conduct virus removal and maintenance on their online shopping equipment, randomly download unidentified junk software and access to the spam website. This may provide a chance for cyber hackers to secretly steal personal information of consumers and further cause a large amount of leakage of consumers' personal information.

3) Consumers have deficient legal knowledge and weak awareness of rights protection: Some consumers may even not realize that their legal rights and interests have been invaded at all after their personal information has been leaked and generated certain consequences, due to lacking of legal knowledge. Even if consumers realize that their legal rights and interests are invaded, they do not know how to 
protect their legal rights and interests in a legal way. Eventually, their legal rights and interests are invaded and the lawbreakers are at large.

\section{MEASURES FOR PROTECTING CONSUMERS' PERSONAL INFORMATION SECURITY IN THE EXPRESS INDUSTRY}

\section{A. Perfecting the Internal Supervision System of Express Companies and Improving the Quality of Express Practitioners}

Express companies also need to set up and perfect an internal supervision system and management mechanism based on actual conditions and improve the entire quality of express practitioners to upgrade the service of the entire express industry to a new level. In order to achieve this goal, it is necessary to realize the following three points:

- Set up and perfect the induction training system for express practitioners, enlarge the extent of training for professional quality of express workers especially for express practitioners, regularly make comprehensive assessments on express practitioners and give spiritual and material rewards to employees who are ranked top in the evaluation result in the end of the year so as to motivate other employees;

- Improve the legal knowledge of express practitioners so that the practitioners can further make clear that leaking consumers' personal information is an illegal and criminal behavior and it is necessary to completely eradicate such occurrences from the source of thought;

- Further rigorously regulate express information transfer and express waybill preservation system, strictly keep confidential the information on conveying status of the express and personal information of consumers and improve the information privacy management capability of express companies;

\section{B. Perfecting the Legal System for Protection of Personal Information}

With the development of economic globalization, the commercial value of personal information is infinitely expanded so that illegal and criminal behaviors of leaking personal information through various methods are increasing day by day. Therefore, consumers have to pay close attention to the protection of their personal information. However from the perspective of the existing laws and regulations on the protection of personal information in China, it is obviously not keeping pace with the development of the times. Relevant laws and regulations are not only less in quantity but also disorderly in distribution, without clear punishment provisions, and it is not very effective to implement. In face of such a situation, in order to set up a sound legal system for personal information protection, it is necessary to realize the following two points: first, the national legislature should speed up the formulation of "Personal Information Security Protection Law", defining the scope of personal information, determining the position of personal information right and establishing the legal responsibilities to be undertaken by the one leaking the personal information so that judicial organs can truly judge such case according to law. Second, China should formulate a "Provisions for Management of Express Industry" to clarify the content and scope of personal information that can be collected by the express company in its business activities. Workers of the express company should be prohibited to arbitrarily expand the scope of information collection or even disclose, sell or illegally provide others the consumers' personal information for other purpose than express service; otherwise, the worker shall undertake corresponding legal responsibility.

\section{Raising Consumers' Consciousness of Self-protection of Personal Information in Express Industry}

Consumers' weak consciousness of self-protection on their personal information provides a chance for lawbreakers to take advantage of it and even to a certain extent strengthened the psychology of criminals to steal consumers' personal information through various methods and ways. Although we should not blame consumers who are treated unfairly, consumers themselves paying attention to improving their personal information protection awareness are an important guarantee for safeguarding their legal rights and interests. First, it is needed to take advantage of various media to vigorously disclose the link in express service process that may leak consumers' personal information so that consumers can take targeted precautions when accepting express service. Second, after receiving the express mail, consumer cannot discard the express waybill containing personal information or randomly throw away the packaging box pasted with the express waybill. Even if it is to be thrown away, it is necessary to tear up or blacken the express waybill to the extent that the personal information on it cannot be recognized any more, so as to get rid of any chance for criminals. Third, if personal information is leaked, consumers should dare to safeguard their rights, maintain due diligence, promptly complain to the administrative department, or seek the help of the association of consumers. If necessary, they can safeguard their legal rights and interests through judicial procedures. If consumers bravely take legal weapons to fight against criminals, they may get criminals exposed and punished accordingly while safeguarding their legal rights and interests.

\section{Playing the Self-discipline and Social Supervision Role of Express Industry}

The industry association can set up special customer complaint departments to receive complaints from consumers and assist judicial organs and administrative authorities to impose strict punishment on those express companies and practitioners that leak consumers' personal information. At the same time, we must also use the power of social supervision, especially through mass media such as radio and television, newspapers and magazines and the Internet, to expose and criticize the behavior of leaking consumers' personal information. For example, since 1991, the China Consumers Association has cooperated with CCTV to hold the " 3.15 " evening party every year, exposed a large number of typical cases about invading consumers' rights, including many cases where express companies and 
their employees leak consumers' personal information. After exposure through media, it not only discloses the illegal business and imposes legal sanctions on such business but also improves the awareness and ability of consumers to protect their rights.

\section{CONCLUSION}

In short, the rapid development of express industry also brings hidden danger to security of consumers' personal information while providing convenience to consumers. Only by really protecting personal information of consumers from being infringed under the premise of ensuring orderly circulation of information from the perspective of different precautions, can it be available to promote the healthy, sustainable and stable development of express industry.

\section{REFERENCES}

[1] Wu Lidong, Xu Junji, Yan Wei. Research on countermeasures for protecting consumers' information security in express industry in the era of e-commerce [J], Intelligence, 2017(3). (in Chinese)

[2] Meng Qiang. On the security and protection of consumers' personal information in express delivery industry [J], Logistics Sci-Tech, 2016 (6). (in Chinese)

[3] Tan Xiuli, Zhang Maoxin, Ai Mingyue. Research on legal protection of consumers' personal information in express industry [J], Daqing Social Sciences, 2017(4). (in Chinese)

[4] Zhou Wenwen, Lei Jianye. A brief analysis of consumers' personal information protection in express industry [J], Legality Vision, 2018 (8). (in Chinese)

[5] Deng Jinghua, Fang Chen. Consumer information protection under the express real name System [J], Legality Vision, 2017 (8). (in Chinese) 